\title{
As influências das dimensões da confiança, identificação organizacional e motivação no desempenho individual
}

Esta pesquisa abordou as dimensões da confiança nos colegas, no chefe, na organização, identificação organizacional e motivação com o desempenho individual. O objetivo foi quantificar as influências das dimensões da confiança, identificação organizacional e motivação no desempenho individual. Para atender o objetivo, utilizou-se a pesquisa descritiva com abordagem quantitativa, com a aplicação de questionário eletrônico para empregados de empresas de TI no período de janeiro e fevereiro de 2019, onde maioria, (92,5\%) trabalha em Minas Gerais. A amostra coletada foi composta por homens $(72,2 \%)$ e mulheres $(27,8 \%)$, sendo que $91,8 \%$ não exerciam a função de chefia. Das 12 hipóteses levantadas, 6 foram confirmadas e apresentaram capacidade de explicação significativa com $R^{2}$ de $65,0 \%$ sobre o desempenho individual. O modelo estrutural apresentou um GoF $=67,73 \%$. Chamou a atenção a força das relações entre Confiança na Organização ( $\beta=$ $0,57)$ com Identificação Organizacional, Identificação Organizacional $(\beta=0,47)$ com Motivação e Motivação $(\beta=0,52)$ com Desempenho Individual.

Palavras-chave: Confiança; Identificação Organizacional; Motivação; Desempenho Individual.

\section{The influences of the dimensions of trust, organizational identification and motivation on individual performance}

This research addressed the dimensions of trust in colleagues, in the boss, in the organization, organizational identification and motivation with individua performance. The objective was to quantify the influences of the dimensions of trust, organizational identification and motivation in individual performance. To meet the objective, descriptive research with a quantitative approach was used, with the application of an electronic questionnaire for employees of IT companies in the period from January to February 2019, where the majority (92.5\%) work in Minas Gerais. The sample collected was composed of men (72.2\%) and women $(27.8 \%)$, with $91.8 \%$ not exercising the leadership role. Of the 12 hypotheses raised, 6 were confirmed and showed significant explanatory capacity with an $\mathrm{R}^{2}$ of $65.0 \%$ on individual performance. The structural model presented a GoF $=67.73 \%$. The strength of the relationships between Trust in the Organization ( $\beta=0.57$ ) with Organizational Identification, Organizational Identification $(\beta=0.47)$ with Motivation and Motivation $(\beta=0.52)$ with Individual Performance drew attention.

Keywords: Confidence; Organizational Identification; Motivation; Individual Performance.

Topic: Comportamento Organizacional

Reviewed anonymously in the process of blind peer.
Received: 08/01/2021

Approved: 24/03/2021
Amaro Rates de Carvalho (iD

Universidade FUMEC, Brasil

http://lattes.cnpq.br/0834460998379844

http://orcid.org/0000-0001-6576-2135

amaro.rates@gmail.com

Mário Teixeira Reis Neto (iD

Universidade FUMEC, Brasil

http://lattes.cnpq.br/2491917845341323

http://orcid.org/0000-0002-4429-8457

reisnetomario@gmail.com
Referencing this:

CARVALHO, A. R.; REIS NETO, M. T.. As influências das dimensões da confiança, identificação organizacional e motivação no desempenho individual. Revista Brasileira de Administração Científica, v.12, n.1, p.352-366, 2021. DOI: http://doi.org/10.6008/CBPC2179684X.2021.001.0029 


\section{INTRODUÇÃO}

No mundo dos negócios com competição acirrada, mudanças constantes e novas tecnologias, as organizações precisam de bons desempenhos para sobreviverem com lucratividade. No livro de Bergamo Filho (2019), é ressaltado a importância do conhecimento para a evolução de um país e que a patente atesta esse conhecimento. Informa que o Brasil demora até 14 anos para gerar uma patente, enquanto muitos países levam menos de 1 ano. Isso gera grande perda de competitividade para o Brasil. Nesse contexto, fica perceptível a desvantagem das organizações de países em desenvolvimento para gerar valor agregado aos produtos e ter desempenho de igual para igual com as organizações de países desenvolvidos. Isso pode gerar incertezas dentro e fora das organizações, como incerteza sobre demanda, evolução tecnológica, política, regulamentação, competição, mudanças, podendo afetar o comportamento dos profissionais e restringir a confiança.

Conhecer o efetivo desempenho individual dos empregados, assim como os desempenhos das equipes de trabalho que Ihes são subordinadas, é uma preocupação recorrente de gestores das mais diferentes organizações e setores de atuação. Desde o final do século XIX até os dias de hoje, o que não faltam são tentativas de sistemas de medição que sanasse essa necessidade, nos mais diferentes cenários (LUGOBONI et al., 2014).

A Confiança tende a ser um direcionador de atitudes positivas. A partir dos anos 50, a confiança já havia sido percebida como elemento norteador e delimitador das relações humanas. Assim, a confiança vem sendo pesquisada sob diversas perspectivas: relacionamentos entre organizações distintas; entre organizações coligadas; entre indivíduos e organizações; entre indivíduos; entre indivíduos e instituições sociais. A confiança tem afetado o ambiente organizacional, na medida em que contribui para a diminuição dos custos de transação, redução dos contratos formais, além da resolução de disputas entre as organizações. Também sendo importante na construção de uma nova concepção de hierarquia (DINIZ et al., 2010).

Quando existe relação de confiança entre as pessoas, cresce a probabilidade de trocas e compartilhamento de informações, reduzem-se os conflitos e aumentam a identificação organizacional, motivação e desempenho organizacional. As relações de confiança podem operar como um mecanismo de redução de incertezas (ZANINI et al., 2014).

Em linha com o entendimento que a confiança pode influenciar no Desempenho do Empregado, a Motivação também pode ter influência direta nessa relação. Alguns autores descrevem a pesquisa realizada por William James, está aponta que um trabalhador conseguiria manter o seu emprego com apenas $20 \%$ a $30 \%$ da sua capacidade produtiva. Porém, se os mesmos fossem altamente motivados, conseguiriam utilizar de $80 \%$ a $90 \%$ de sua capacidade. Isso significa que havendo pouca motivação, consequentemente o desempenho do empregado será reduzido. Os autores concluíram, portanto, que a motivação consegue influenciar em até $70 \%$ do desempenho do empregado.

Outro fator que pode afetar a relação empregado e organização é a Identificação Organizacional, 
por sua vez, tem merecido um papel de destaque em toda essa nova maneira de se enxergar e lidar com as pessoas e os desafios em equipe. Um funcionário que se identifica com a organização, estará mais propenso a se dedicar e a partir de aí aumentar a qualidade e a quantidade da sua entrega. Alguns autores mostram o quanto as questões culturais e de valores, influenciam nessa relação entre o empregado e a organização e creem que existe, neste ponto, uma grande oportunidade para as orientações, uma vez que buscando se comunicar de modo a encorajar a identificação dos empregados, elas poderão contar com pessoas cada vez mais envolvidos e dispostas a realizarem um bom trabalho.

A questão norteadora desse trabalho (qual a influência das dimensões da confiança, identificação organizacional e motivação no desempenho individual do empregado?) tem como objetivo principal mensurar as relações das influências das dimensões da confiança, identificação organizacional e motivação no desempenho individual do empregado. E se justifica cientificamente devido ao cenário de conhecimento desfavorável que os países em desenvolvimento se encontram em relação aos países desenvolvidos e a falta de pesquisas científicas com modelos estruturais que ajudam no desempenho individual, faz se necessário criar um modelo que seja capaz de mostrar os caminhos para melhorar o desempenho individual. Sob o ponto de vista gerencial, este trabalho se justifica porque pode contribuir para melhorar o desempenho individual e a gestão de recursos humanos dentro das organizações. Através dos resultados e do modelo teórico proposto e validado a organização pode implementar ações práticas para avaliar os indivíduos e buscar mais confiança, identificação na organização, motivação e desempenho do indivíduo.

Espera-se que o resultado dessa pesquisa possa impulsionar pesquisas futuras sobre o tema. Consequentemente, gerar um modelo que poderá ser aplicado no âmbito acadêmico e organizacional, integrando teoria e pratica.

\section{REVISÃO TEÓRICA}

\section{Confiança}

Dursun (2015) apresenta um conceito de confiança direcionado à organização, que diz no sentido mais geral que a confiança é percebida como honestidade e um conceito baseado na verdade. Confiança compreende a crença em compromissos de um indivíduo ou grupo com seus comportamentos e intenções, suas expectativas em relação a comportamentos morais, justos e construtivos, e considerando os direitos dos outros. O construto confiança pode e deve ser aplicado em praticamente todas as áreas, como social, organizacional, política, psicologia, ciência política, sociologia, economia e gestão, entre outras.

\section{Confiança na organização}

Para Searle (2015) a confiança tem mérito teleológico, pois a confiança oferece benefícios práticos significativos para as organizações. Aponta que as organizações com maior confiança têm maior eficácia, eficiência e desempenho. Demonstra que funcionários com alto nível de confiança nas organizações colocam grande esforço em suas funções e participam de forma mais cooperativa com os outros, enquanto aqueles 
que não confiam em suas organizações empregadoras trabalham de maneira menos eficaz ou simplesmente saem.

No estudo de Araújo et al. (2008) em organizações privadas da Região do Triângulo Mineiro, os participantes responderam aos seguintes instrumentos: valores organizacionais, confiança, satisfação no trabalho, comprometimento afetivo e envolvimento com o trabalho. Os resultados mostraram que o principal preditor de comprometimento afetivo foi a confiança nos padrões éticos da organização e posteriormente promoção do crescimento do empregado. Para Batista et al. (2012), no âmbito organizacional a confiança passou a ser mais importante depois que as relações entre organizações e entre estas e seus empregados se tornaram formais. A formalidade pode deixar a relação fria se não for respeitado um conjunto de cognições interdependentes que integra crenças a respeito de padrões éticos, credibilidade da comunicação, poder econômico da organização e capacidade desta de reconhecer o desempenho do empregado, tanto financeira quanto profissionalmente. Este esquema mental representa um conjunto de crenças do empregado sobre a manutenção de padrões éticos, a solidez econômica da organização e a capacidade desta em reconhecer os esforços dos empregados, honrar compromissos, obedecer a leis e normas.

\section{Confiança no chefe}

Dirks (2006) entende que os chefes desempenham um papel importante nas organizações, particularmente do ponto de vista dos subordinados. O poder formal e informal que os chefes possuem coloca-os em posição de influenciar significativamente os subordinados à medida que estabelecem as metas para as quais os indivíduos trabalham, controlam os recursos que valorizam e tomam decisões que afetam suas compensações e carreiras. Como consequência, os subordinados têm interesse significativo em avaliar se podem ou não confiar nos chefes. Embora o reconhecimento da centralidade da confiança nos chefes seja motivo de preocupação para os subordinados, só recentemente ele assumiu um papel proeminente na pesquisa organizacional.

Uma pesquisa realizada por Lee (2016) com base na teoria da troca social e na teoria da identidade social, examinou a influência da liderança ética nos seguidores, assumindo a mediação da confiança no líder e da identificação com o líder. Usando dados obtidos de oficiais de baixa patente e seus supervisores imediatos na Marinha sul-coreana, descobriu que tanto a confiança no líder quanto a identificação com o líder mediavam completamente a relação entre a liderança ética e os seguidores que assumiam o comando. Os resultados destacam a importância do compromisso com o líder (ou seja, confiança no líder e identificação com o líder) como um mecanismo através do qual a liderança ética influencia os resultados positivos do trabalho para a organização.

\section{Confiança nos colegas}

Seja no contexto social ou no organizacional, a confiança é gerada através da relação transparente que permite um indivíduo conhecer o outro, e vice-versa. No trabalho de Moori et al. (2007) foi realizado um 
estudo de caso numa empresa que atua no mundo todo no ramo de papel e celulose. $O$ objetivo do estudo foi mapear a contribuição da colaboração dos funcionários na melhoria do desempenho do planejamento colaborativo. Com base no referencial teórico os autores chegaram nas variáveis independentes de quando há colaboração dos funcionários: a confiança; o comprometimento; e o trabalho em equipe. Os resultados apontaram os respectivos escores: $4,3-4,3-4,0$, numa escala que variou de 1 a 6 , onde 1 corresponde ao pior caso e 6 o melhor. Isso foi permitido, em boa parte, pelo grau de confiança existente entre os funcionários e a organização. Esse mesmo estudo remete a um estudo semelhante realizado em 2003, usando os mesmos dados desta pesquisa numa empresa inglesa do ramo químico, que mostrou a confiança como o aspecto mais valorizado na colaboração.

Numa pesquisa realizada por Schaubroeck et al. (2013) com soldados do Exército dos Estados Unidos para compreender como pares e líderes influenciam o ajuste dos recém-chegados a uma organização ou profissão examinando como percepções específicas de confiança. Foi usado um modelo de como a confiança baseada em afetividade em um líder e colegas de unidade de trabalho se desenvolve a partir de uma base de confiança formada em cognição e, posteriormente, influencia a identificação organizacional e o desempenho relacionado ao papel. Os resultados demonstraram que quando os novatos são recebidos com benevolência pelos seus pares e recebem as informações e recursos necessários, isso pode criar laços de confiança que facilitam uma socialização mais efetiva.

\section{Identificação organizacional}

O construto identificação organizacional, conforme alguns autores, se caracteriza pelo conjunto de atributos com os quais uma pessoa define aquela empresa ou marca e depende do quão alinhadas estão estes atributos em relação ao que a pessoa valoriza individualmente. Os autores acrescentam também que quanto maior está identificação, maior será o vínculo entre o empregado e a empresa.

O conceito de identificação organizacional, baseada na teoria da identidade social, sugere que os empregados se identifiquem com uma organização quando sua identidade pessoal, ou seja, os valores e crenças pessoais são semelhantes e quando a filiação com a organização aumenta a autoestima e o bemestar daquele empregado (ZAGENCZYK et al., 2011).

Para Zagenczyk et al. (2011) a relação se torna tão profunda que os empregados, por vezes passam a incorporar a identidade da organização em sua própria identidade social. Os sucessos e falhas da organização passam a afetar pessoalmente os empregados: os sucessos aumentam e as falhas diminuem a autoestima dos empregados.

Assim, como resultado da identificação, os empregados tendem a ser mais comprometidos, mais aptos a se envolver em comportamentos de cooperação atrelados ao direcionamento organizacional e são menos propensos a saírem em busca de novas oportunidades de emprego. Assim como os empregados identificam quando percebem que existe similaridade entre eles próprios e suas organizações, eles também se distanciam caso esta conexão passe a não existir, quando percebem que existem diferenças fundamentais entre as próprias conviç̧ões e as da organização, quando percebem que a organização tem valores diferentes 
dos seus, quando eles acreditam que a reputação da organização é desfavorável, ou quando percebem que sua identidade está ameaçada por esta relação.

\section{Motivação}

As relações interpessoais são a base de bons relacionamentos e desempenhos no ambiente de trabalho, uma vez que o ser humano depende fortemente de seu bem-estar para que consiga produzir o melhor de si. A motivação dos empregados em especial tem merecido bastante atenção dos gestores contemporâneos, por ser algo que representa diretamente o que pode se esperar daquele empregado. Alguns autores conceituam motivação como 'as forças dentro de uma pessoa responsáveis pelo nível, direção e persistência de esforço despendido no trabalho'. Reconhecendo o aspecto pessoal da motivação, um autor deixa claro que 'O processo motivacional é sempre íntimo e pessoal. É essencial entender o sentido que cada um atribui ao trabalho que realiza'.

Falar de motivação passa necessariamente pelo reconhecimento, este sentimento é um importantíssimo aliado de um gestor. Conforme explanado por Nelson (2014), é a maneira que reage uma pessoa em relação ao que ela esperava do resultado de outra pessoa. Existem inúmeras maneiras de se dar reconhecimento a um empregado: sejam elas formais, através do registro via e-mail ou prêmios antecipadamente criados e comunicados a todos; Informais, que se caracterizam por reconhecimentos espontâneos e naturais, como levar o empregado para almoçar em agradecimento ao belo trabalho executado, solicitar opiniões, envolver os empregados nas tomadas de decisões; Ou até os reconhecimentos diários, que podem ser feitos sempre nas reuniões de bom dia, com a equipe reunida e funcionam com apenas um 'bom trabalho', dito de maneira natural e pessoal. Todo reconhecimento será melhor aceito se dito logo após ou enquanto o empregado está se esforçando para alcançar aquela meta em questão.

Conforme Pérez-Ramos (1990), caso o empregado se sinta numa situação de "inequidade" tanto subcompensado quanto supercompensado, o mesmo agirá de modo a tentar buscar um equilíbrio de ações e recompensas. Seja este equilíbrio variando a sua própria atuação, aumentando ou diminuindo seus níveis de empenho, ou mesmo buscando influenciar o empenho dos demais colegas. Tentativas estas que, se frustradas, podem até culminar num abandono do emprego.

O estudo das Ciências Sociais e o próprio cenário competitivo existente entre as empresas faz perceber-se que muitas retribuições não financeiras têm um impacto tão relevante no dia a dia do profissional quanto as financeiras. Torna-se claro que os gestores devem buscar incentivar não apenas financeiramente os seus empregados, mas compreender que o reconhecimento e o incentivo são elementos essenciais para motivar os empregados.

\section{Desempenho individual na organização}

O desempenho individual é uma das principais variáveis que os psicólogos profissionais e organizacionais desejam explicar e prever em suas pesquisas. Da mesma forma, muitas técnicas e programas de intervenção implementados nas organizações visam a melhoria do desempenho individual (SONNENTAG 
et al., 2002). Neste tópico será apresentado o conceito de desempenho individual na organização, será contextualizado mostrando sua importância e também os principais tipos de modelos de avaliação de desempenho estudados pelos pesquisadores.

\section{Definição de desempenho individual na organização}

O tema desempenho tem uma grande relevância acadêmica e prática, pois é um construto comportamental capaz de englobar importantes dimensões psicossociais, individuais, interpessoais e situacionais, bem como, um dos grandes geradores de valor para os indivíduos, equipes e consequentemente, para as organizações. Existem vários desafios que tangem os estudos de desempenho organizacional e, conforme explanado por Brito et al. (2016), a interação entre a abordagem teórica e as observações do dia a dia das organizações é algo bastante complexo, devido à multidimensionalidade do conceito de desempenho. Para Bendassolli (2012), o desempenho é certamente uma das dimensões nevrálgicas quando se fala em gestão de pessoas, uma vez que é “um construto comportamental, isto é, uma ação ou conjunto de ações realizadas pelo indivíduo e que contribuem para o alcance de objetivos organizacionalmente relevantes" (BENDASSOLLI, 2012).

Borges et al. (2013) afirmam que desempenho é um conjunto de comportamentos ou atividades tácitas ou explícitas que demonstramos em determinadas situações e dependem de nossa ação esperada. É a execução de um trabalho, ação ou empreendimento, algo que exige competência prévia ou efetividade na execução. O produto de uma ação ou manifestação de algum comportamento resulta em desempenho.

\section{Contextualização de desempenho individual na organização}

O atual cenário de competitividade e complexidade dos mercados concorrenciais tem contribuído para que, segundo Lugoboni et al. (2014), seja cada vez mais complicado e mais importante a mensuração de desempenho dos empregados da organização, uma vez que o que não é medido, não é gerenciado e empresas com ausência de controle e que não tiram os melhores resultados de seus recursos, estão fadadas a perderem espaço no mercado.

O desempenho individual é de suma importância para as organizações e para o indivíduo. Para organização porque indivíduos com alto desempenho colaboram para o alcance dos objetivos organizacionais e auxiliam na obtenção de vantagens competitivas. Para o indivíduo porque pode ser uma fonte de satisfação, gerando sentimentos de domínio e orgulho ou, no caso do baixo desempenho e do não alcance de resultados, pode ocasionar insatisfação e sensação de fracasso pessoal. No entanto, se o desempenho for reconhecido por outras pessoas dentro da organização, a probabilidade de crescimento, reconhecimento no mercado e benefícios financeiro aumenta, visto que o desempenho é um dos principais pré-requisitos para o desenvolvimento profissional (SONNENTAG et al., 2002).

O trabalho de Matitz et al. (2011) defende que "compreender a natureza do conceito de desempenho contribui para a superação do desafio teórico contínuo da compreensão das complexidades organizacionais". Os autores enfatizam que apesar desse construto ser tão amplamente utilizado nas pesquisas em 
administração ainda não há uma teoria empírica universal de mensuração. Tendo em vista a natureza multidimensional do conceito de desempenho, este deve ser compreendido e devidamente considerado em relação à sua amplitude e profundidade.

\section{Modelos de Avaliações de Desempenho individual na organização}

Tendo em vista a importância do desempenho individual, tanto para o indivíduo, quanto para a organização. Também que é um tema complexo, pois é multidimensional e apesar das organizações entender sua importância, essas procuram sempre melhores formas de avaliações, que nem sempre traz resultados satisfatórios. Para que seja possível realizar avaliações, Sonnentag et al. (2002) reconhece que o desempenho é um conceito multidimensional.

Vários autores realizaram trabalhos focados em criar modelos para o desempenho individual. A tabela 1 resume a revisão dos principais modelos de desempenho no trabalho apresentado na pesquisa de (BENDASSOLLI, 2012).

Tabela 1: Resumo dos principais autores da literatura sobre desempenho.

\begin{tabular}{|c|c|c|c|}
\hline Modelo & Autores & Propostas & Principais elementos \\
\hline 1 & Murphy (1989a; 1989b) & $\begin{array}{l}\text { Desempenho como conceito } \\
\text { dinâmico e multidimensional }\end{array}$ & $\begin{array}{l}\text { Importância das habilidades e de varáveis } \\
\text { disposicionais como causas do desempenho variam } \\
\text { segundo dois estágios: } \\
\text { - Estágio de transição; } \\
\text { - Estágio de manutenção; } \\
\text { As dimensões propostas pelo autor são: } \\
\text { - Comportamentos orientados para tarefa; } \\
\text { - Comportamentos interpessoais; } \\
\text { - Comportamento de indisponibilidade; } \\
\text { - Comportamentos destrutivos; }\end{array}$ \\
\hline 2 & $\begin{array}{l}\text { Campbell (1990); Campbell et } \\
\text { al. (1993); Campbell et al. } \\
(1996)\end{array}$ & $\begin{array}{l}\text { Taxonomia de componentes } \\
\text { do desenvolvimento e seus } \\
\text { determinantes }\end{array}$ & $\begin{array}{l}\text { Três determinantes do desempenho: } \\
\text { - Conhecimento declarativo; } \\
\text { - Conhecimentos procedimentais e habilidades; } \\
\text { - Motivação. } \\
\text { Desempenho constituído por oito componentes: } \\
\text { - Proficiência em tarefas específica ao cargo; } \\
\text { - Proficiência em tarefas não específicas ao cargo; } \\
\text { - Comunicação oral e escrita; } \\
\text { - Demonstração de esforço; } \\
\text { - Manutenção da disciplina pessoal; } \\
\text { - Facilitação para pares e desempenho de equipe; } \\
\text { - Supervisão e liderança; } \\
\text { - Gestão. }\end{array}$ \\
\hline 3 & Borman et al. (1993) & $\begin{array}{l}\text { Desempenho como conceito } \\
\text { multidimensional }\end{array}$ & $\begin{array}{l}\text { Desempenho de tarefa: } \\
\text { - Contribuição para o core técnico do cargo; } \\
\text { Desempenho contextual: } \\
\text { - Persistência e esforço na realização de tarefas; } \\
\text { - Realizar tarefas voluntariamente, extra papel; } \\
\text { - Seguir regras e procedimento; } \\
\text { - Ajudar a cooperar com os outros; } \\
\text { - Apoiar e defender os objetivos organizacionais; }\end{array}$ \\
\hline 4 & $\begin{array}{l}\text { Frese et al. (1994); Roe } \\
\text { (1999); Frese et al. (2001); } \\
\text { Sonnentag (1998) }\end{array}$ & Desempenho ativo & $\begin{array}{l}\text { Desempenho é visto como um processo de ação } \\
\text { regulado pela sequência: } \\
\text { - Estabelecimento de objetivos; } \\
\text { - Busca de informação; } \\
\text { - Planejamento; } \\
\text { - Monitoramento; } \\
\text { - Feedback; } \\
\text { o desempenho ativo é resultado de ações } \\
\text { disparadas por iniciativas pessoal, à qual é composta }\end{array}$ \\
\hline
\end{tabular}




\begin{tabular}{|c|c|c|c|}
\hline & & & $\begin{array}{l}\text { por três facetas: } \\
\text { - Autoiniciativa; } \\
\text { - Proatividade; } \\
\text { - Persistência; }\end{array}$ \\
\hline 5 & $\begin{array}{l}\text { Pulakos et al. (2000); Pulakos } \\
\text { et al. (2002); Griffin et al. } \\
\text { (2007) }\end{array}$ & Desempenho adaptativo & $\begin{array}{l}\text { O desempenho é uma ação situacional e adaptativa } \\
\text { expressa em oito dimensões: } \\
\text { - Lidar com emergências ou situações de crise; } \\
\text { - Lidar com stress no trabalho; } \\
\text { - Resolver problemas criativamente; } \\
\text { - Lidar com situações de trabalho incertas e } \\
\text { imprevisíveis; } \\
\text { - Aprender tarefas, tecnologias e procedimentos } \\
\text { relacionados ao trabalho; } \\
\text { - Demonstrar adaptabilidade interpessoal; } \\
\text { - Demonstrar adaptabilidade cultural; } \\
\text { - Demonstrar adaptabilidade física. }\end{array}$ \\
\hline 6 & Beal et al. (2005) & Desempenho episódico & 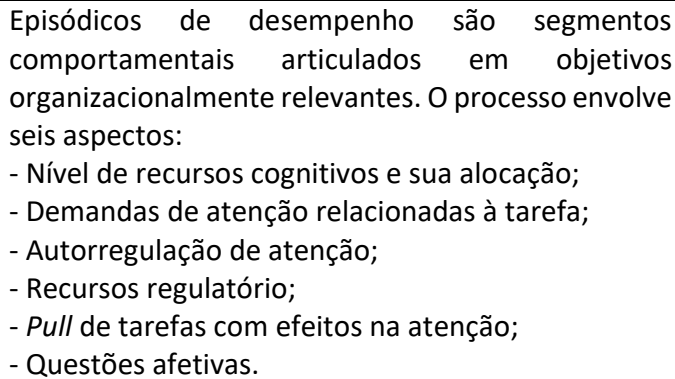 \\
\hline
\end{tabular}

Fonte: adaptado de Bendassolli (2012).

O primeiro modelo, de Murphy (1989), enfatiza a natureza dinâmica do desempenho, esclarecendo que o mesmo oscila ao longo do tempo, em estágios de transição (em que o trabalho e a tarefa são novos e demandam aprendizado) e manutenção (a tarefa já foi aprendida e depende agora de fatores intencionais).

O segundo modelo e um dos mais citados é o modelo proposto por Campbell (1993). Conforme Bendassolli (2012), o desempenho é abordado como um comportamento ou uma ação relevante para os objetivos da organização e pode ser medido de acordo com níveis ou margens de contribuição. O destaque do modelo é a proposta de dimensões determinantes e preditivas ao desempenho. Os determinantes são o conhecimento declarativo, que diz respeito do que fazer; conhecimento dos procedimentos e habilidades que se refere ao como fazer; e, por fim, a motivação que se relaciona a escolher quando e por que fazer. Nesse modelo o desempenho é composto por oito componentes: proficiência em tarefas específicas para o cargo; proficiência em tarefas relativas não ao cargo; comunicação oral e escrita; demonstração de esforços; manutenção da disciplina pessoal; facilitação para pares e desempenho de equipe; supervisão e liderança; e gestão.

O terceiro modelo, de Borman et al. (1993), desenvolve duas dimensões distintas que analisam o desempenho: desempenho da tarefa (capacidade de executar tarefas e agregar valor conforme expectativa da posição) e desempenho contextual (que não está atrelado diretamente à parte técnica, mas que traz contribuições indiretas à tarefa específica). Bendassolli (2012) esclarece que o desempenho de tarefa oscila em relação às atribuições específicas dos cargos e habilidades dos empregados, e o desempenho contextual é mais vulnerável a aspectos motivacionais e de personalidade.

O quarto modelo, engloba um desempenho ativo, baseado em duas premissas: os seres humanos são essencialmente seres de ação e essa ação é sempre orientada por um objetivo, de modo que o sujeito 
da ação é um sujeito intencional, capaz de regular-se a si mesmo e orientar-se em busca desse objetivo.

O quinto modelo, elaborado por Pulakos et al. (2000), Pulakos et al. (2002), denominado de desempenho adaptativo, parte do princípio de que o indivíduo deve continuamente adaptar seu desempenho às mudanças e às situações referentes ao trabalho, principalmente às mudanças tecnológicas e relacionadas com a globalização.

O sexto modelo, de Beal et al. (2005), contempla o desempenho episódico. Pelo fato de estados afetivos serem bastante dinâmicos e transitórios, os autores postularam o conceito de desempenho como a progressão temporal das atividades de trabalho de uma pessoa ao longo do dia. O ponto-chave do modelo é o modo de alocação de recursos cognitivos como: as habilidades cognitivas gerais, os conhecimentos relacionados à tarefa e o fator "consciência" do modelo de personalidade dos cinco fatores: 1) neuroticismo ou instabilidade emocional; 2) extroversão; 3) amabilidade; 4) escrupulosidade; e 5) abertura para a experiência (BENDASSOLLI, 2012).

\section{METODOLOGIA}

A presente pesquisa pode ser classificada como quantitativa, descritiva, conclusiva para a amostra estudada. O modelo hipotético formulado a partir das relações entre variáveis apresentadas pode ser visto na Tabela 3 devido à limitação de espaço. Foi utilizado um questionário estruturado com escala tipo Likert de 1 a 10 pontos. A pesquisa foi realizada com 162 indivíduos que responderam a 46 itens, sendo 7 itens de caracterização e 39 itens relacionadas a 10 constructos de primeira ordem. 0 tratamento estatístico foi realizado utilizando-se a abordagem PLS (Partial Least Squares).

\section{RESULTADOS}

Das variáveis categóricas caracterizadoras, pode-se destacar que 37,7\% dos indivíduos estavam entre 30 a 40 anos de idade, 72,2\% dos indivíduos eram do sexo masculino, 50,6\% dos indivíduos tinham Pósgraduação completa, 92,5\% dos indivíduos tinham o Local de trabalho em Minas Gerais, 46,3\% dos indivíduos tinham renda pessoal acima de $\mathrm{R} \$ 6.000,00$. Do total da amostra, 38,1\% dos indivíduos tinham de 2 a 5 anos de tempo de trabalho na empresa e 91,8\% não exerciam função de chefia.

Sobre as medidas de validação dos constructos vale destacar que houve validação convergente em todos os constructos, visto que todos apresentaram AVEs superiores a 0,40. Os indicadores de Alfa de Cronbach (A.C.) ou de Confiabilidade Composta (C.C.) apresentaram valores acima de 0,70 em todos os constructos, portanto, todos constructos atingiram os níveis exigidos de confiabilidade. Todos constructos apresentaram valores de KMO iguais ou superiores a 0,50, evidenciando assim que o ajuste da Análise Fatorial foi adequado em todos. De acordo com o critério de Kaiser todos os constructos foram unidimensionais.

Sobre as medidas de validação dos constructos são destaque houve validação convergente em todos os constructos, visto que todos apresentaram AVEs superiores a 0,40 . Os indicadores de Alfa de Cronbach (A.C.) ou de Confiabilidade Composta (C.C.) apresentaram valores acima de 0,70 em todos os constructos, 
portanto, todos constructos atingiram os níveis exigidos de confiabilidade. Todos constructos apresentaram valores de KMO iguais ou superiores a 0,50, evidenciando assim que o ajuste da Análise Fatorial foi adequado em todos. De acordo com o critério de Kaiser todos os constructos foram unidimensionais.

Sobre a análise da validade convergente, a validade discriminante, dimensionalidade e a confiabilidade dos construtos do modelo de mensuração final pode-se destacar que em todos os constructos, os índices de confiabilidade A.C. ou C.C. apresentaram valores acima de 0,60, evidenciando assim a confiabilidade dos mesmos. Pelo critério de Kaiser todos os constructos foram unidimensionais. Todas as AVEs foram superiores a 0,40 , indicando que houve validação convergente em todos os constructos. Pelo critério proposto por um autor houve validação discriminante para todos os constructos, uma vez que as variâncias compartilhadas máximas foram menores que as respectivas AVEs. Os resultados do modelo estrutural são apresentados na Tabela 2.

Tabela 2: Modelo Estrutural.

\begin{tabular}{|c|c|c|c|c|c|}
\hline Endógena & Exógena & $\beta$ & I.C. - $95 \%^{1}$ & Valor-p & $\mathbf{R}^{\mathbf{2}}$ \\
\hline \multirow{3}{*}{ Identificação Organizacional } & Confiança no chefe & 0,11 & {$[-0,05 ; 0,29]$} & 0,091 & \multirow{3}{*}{$69,10 \%$} \\
\hline & Confiança nos colegas & 0,30 & {$[0,11 ; 0,52]$} & 0,000 & \\
\hline & Confiança na Organização & 0,57 & {$[0,39 ; 0,70]$} & 0,000 & \\
\hline \multirow{4}{*}{ Motivação } & Confiança no chefe & 0,20 & {$[-0,03 ; 0,38]$} & 0,010 & \multirow{4}{*}{$55,30 \%$} \\
\hline & Confiança nos colegas & 0,14 & {$[-0,06 ; 0,38]$} & 0,114 & \\
\hline & Confiança na Organização & 0,05 & {$[-0,20 ; 0,27]$} & 0,578 & \\
\hline & Identificação Organizacional & 0,47 & {$[0,13 ; 0,83]$} & 0,000 & \\
\hline \multirow{5}{*}{ Desempenho individual } & Confiança no chefe & 0,03 & {$[-0,13 ; 0,23]$} & 0,643 & \multirow{5}{*}{$65,00 \%$} \\
\hline & Confiança nos colegas & $-0,03$ & {$[-0,22 ; 0,15]$} & 0,719 & \\
\hline & Confiança na Organização & 0,31 & {$[0,12 ; 0,46]$} & 0,000 & \\
\hline & Identificação Organizacional & 0,08 & {$[-0,19 ; 0,43]$} & 0,361 & \\
\hline & Motivação & 0,52 & {$[0,30 ; 0,69]$} & 0,000 & \\
\hline
\end{tabular}

'Erro Padrão; GoF $=67,73 \%$.

Em relação a Identificação Organizacional: Houve influência significativa (valor- $p=0,000$ ) e positiva $(\beta=0,30)$ da Confiança nos colegas sobre a Identificação organizacional. Portanto, quanto maior a Confiança nos colegas, maior tende a ser a Identificação organizacional. Houve influência significativa (valor-p=0,000) e positiva $(\beta=0,57)$ da Confiança na organização sobre a Identificação organizacional. Portanto, quanto maior a Confiança na organização, maior tende a ser a Identificação organizacional. Os indicadores Confiança no chefe, Confiança nos colegas e Confiança na organização foram capazes de explicar $69,10 \%$ da variabilidade da Identificação Organizacional.

Em relação a Motivação: Houve influência significativa (valor- $p=0,010)$ e positiva $(\beta=0,20)$ da Confiança no chefe sobre a Motivação. Portanto, quanto maior a Confiança no chefe, maior tende a ser a Motivação. Houve influência significativa (valor- $p=0,000)$ e positiva $(\beta=0,47)$ do Confiança nos amigos sobre a Motivação. Portanto, quanto maior a Confiança nos amigos, maior tende a ser a Motivação. Os indicadores Confiança no chefe, Confiança nos colegas, Confiança na organização e Identificação Organizacional foram capazes de explicar 55,30\% da variabilidade da Motivação.

Em relação ao Desempenho individual: Houve influência significativa (valor- $p=0,000)$ e positiva $(\beta=0,31)$ da Confiança na organização sobre o Desempenho individual. Portanto, quanto maior a Confiança na organização, maior tende a ser o Desempenho individual. Houve influência significativa $($ valor- $p=0,000)$ e 
positiva $(\beta=0,52)$ da Motivação sobre o Desempenho individual. Portanto, quanto maior a Motivação, maior tende a ser o Desempenho individual. Os indicadores Confiança no chefe, Confiança nos colegas, Confiança na organização, Identificação Organizacional e Motivação foram capazes de explicar 65,0\% da variabilidade do Desempenho individual.

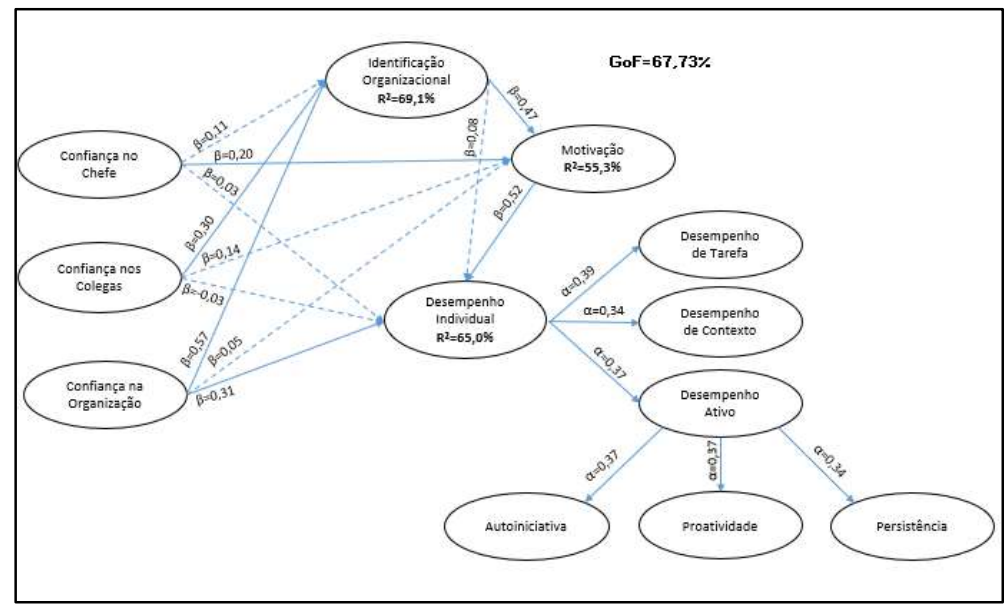

Figura 1: Ilustração do Modelo Estrutural. Fonte: Modelo teórico e hipotético: apoiado em autores referenciados conforme consta na Tabela 4.

\section{Resultados: dados da pesquisa}

Tabela 3: Tabela de Hipóteses e resultados.

\begin{tabular}{|l|l|}
\hline Hipóteses & Resultado \\
\hline H1: Quanto maior a Confiança no Chefe, maior o Identificação Organizacional. & Não confirmado \\
\hline H2: Quanto maior a Confiança nos Colegas, maior o Identificação Organizacional. & Confirmado \\
\hline H3: Quanto maior a Confiança na Organização, maior o Identificação Organizacional. & Confirmado \\
\hline H4: Quanto maior a Confiança no Chefe, maior a Motivação. & Confirmado \\
\hline H5: Quanto maior a Confiança nos Colegas, maior a Motivação. & Não confirmado \\
\hline H6: Quanto maior a Confiança na Organização, maior a Motivação. & Não confirmado \\
\hline H7: Quanto maior a Confiança no Chefe, maior o Desempenho Individual. & Não confirmado \\
\hline H8: Quanto maior a Confiança nos Colegas, maior o Desempenho Individual. & Não confirmado \\
\hline H9: Quanto maior a Confiança na Organização, maior o Desempenho Individual. & Confirmado \\
\hline H10: Quanto maior a Identificação Organizacional, maior a Motivação. & Confirmado \\
\hline H11: Quanto maior a Identificação Organizacional, maior o Desempenho Individual. & Não confirmado \\
\hline H12: Quanto maior a Motivação, maior o Desempenho Individual. & Confirmado \\
\hline
\end{tabular}

\section{DISCUSSÃO}

A tabela 4 a seguir apresenta uma comparação dos resultados desta pesquisa com os resultados obtidos por outros pesquisadores citados no referencial teórico.

Tabela 4: Comparação dos resultados.

\begin{tabular}{|l|l|l|}
\hline Hipóteses & Autores & Essa pesquisa \\
\hline H1: Confiança no Chefe $\rightarrow$ Identificação Organizacional & Lee (2004) - OK & Não validada \\
\hline H2: Confiança nos Colegas $\rightarrow$ Identificação Organizacional & Lee (2004) - OK & Validada \\
\hline H3: Confiança na Organização $\rightarrow$ Identificação Organizacional & Lee (2004) - OK & Validada \\
\hline H4: Confiança na Chefe $\rightarrow$ Motivação & Zanini (2005) - OK & Validada \\
\hline H5: Confiança nos Colegas $\rightarrow$ Motivação & Zanini (2005) - OK & Não validada \\
\hline H6: Confiança na Organização $\rightarrow$ Motivação & Zanini (2005) - OK & Não validada \\
\hline H7: Confiança na Chefe $\rightarrow$ Desempenho Individual & Dirks (2006) - OK & Não validada \\
\hline H8: Confiança nos Colegas $\rightarrow$ Desempenho Individual & Dirks (2006) - OK & Não validada \\
\hline H9: Confiança na Organização $\rightarrow$ Desempenho Individual & Dirks (2006) - OK & Validada \\
\hline H10: Identificação Organizacional $\rightarrow$ Motivação & Hughes et al. (2010) - OK & Validada \\
\hline H11: Identificação Organizacional $\rightarrow$ Desempenho Individual & Lee (2004) - OK & Não validada \\
\hline H12: Motivação $\rightarrow$ Desempenho Individual & Cerasoli et al. (2014) - OK & Validada \\
\hline
\end{tabular}


As hipóteses buscaram investigar a existência do efeito de um construto com os demais. Estudos nesse sentido foram conduzidos por outros autores como pode se verificar no quadro acima. Foram confirmados 6 de 12 hipóteses.

Dentre as 6 hipóteses confirmadas, chamou a atenção a força das relações encontradas entre Confiança na Organização $(\beta=0,57)$ com Identificação Organizacional, Identificação Organizacional $(\beta=0,47)$ com Motivação e Motivação $(\beta=0,52)$ com Desempenho Individual. E os resultados do desempenho ativo, na formação do desempenho individual (tarefa, contexto e ativo), a dimensão tarefa foi a que apresentou maior relevância, $\alpha=0,39$; ativo, $\alpha=0,37$ e contexto, $\alpha=0,34$, confirmou a pesquisa teórica de (FOGAÇA et al., 2018; FRESE et al., 1994; FRESE et al., 2001; SONNENTAG, 1998).

Das 6 hipóteses não confirmadas, vale destacar se que, a confiança no chefe não foi significante sobre a identificação organizacional. As confianças nos colegas e na organização não foram significantes sobre a motivação. As confianças no chefe e colegas não foram significantes sobre o desempenho individual. E por último, a identificação organizacional não influenciou o desempenho individual.

Em resumo, os resultados mostram que para aumentar o desempenho individual de forma mais significativa deve se procurar trabalhar nas questões que promovem a confiança na organização, identificação organizacional e motivação. Pois, estes 3 construtos juntos foram significantes para formação do $\mathrm{R}^{2}$ de $65,0 \%$ sobre o Desempenho Individual. Também deve se trabalhar as questões relacionadas ao desempenho ativo (autoiniciativa, proatividade e persistência), pois o resultado mostrou que esse tipo de desempenho representou $1 / 3$, ou seja $\alpha=0,37$, enquanto tarefa, $\alpha=0,39$ e contexto, $\alpha=0,34$.

\section{CONCLUSÕES}

O objetivo geral da pesquisa foi identificar as influências da confiança no chefe, confiança nos colegas, confiança na organização, identificação organizacional e da motivação no desempenho individual. Para atender a esse objetivo, utilizou-se a pesquisa descritiva com abordagem quantitativa, com a aplicação de questionário eletrônico para os empregados de empresas de TI no período de janeiro e fevereiro de 2019, onde maioria, $92,5 \%$, trabalham em Minas Gerais. Os respondentes são, em sua maioria, homens (72,2\% versus $27,8 \%$ de mulheres), 91,8\% não exercem função de chefia, 37,7\% entre 30 a 40 anos de idade, 50,6\% possuem Pós-graduação, 46,3\% com renda acima de R\$ 6.000,00 e 38,1\% com um tempo de empresa de 2 a 5 anos.

Das 12 hipóteses levantadas nessa pesquisa, 6 foram confirmadas e apresentaram capacidade de explicação significativa com $\mathbf{R}^{\mathbf{2}}$ de $\mathbf{6 5 , 0 \%}$ sobre o Desempenho Individual. Já no que se refere ao desempenho individual (tarefa, contexto e ativo), a dimensão tarefa foi a que apresentou maior relevância, $\boldsymbol{\alpha}=\mathbf{0 , 3 9}$; ativo, $\alpha=\mathbf{0 , 3 7}$ e contexto, $\boldsymbol{\alpha}=\mathbf{0 , 3 4}$.

O modelo estrutural apresentou um GoF $=67,73 \%$, sendo considerado um bom valor, quando comparado com outras pesquisas relacionadas ao tema, mesmo que nem todos construtos sejam iguais. Chamou a atenção a força das relações encontradas entre Confiança na Organização $(\boldsymbol{\beta}=\mathbf{0 , 5 7})$ com 
Identificação Organizacional, Identificação Organizacional $(\boldsymbol{\beta}=\mathbf{0 , 4 7 )}$ com Motivação e Motivação $(\boldsymbol{\beta}=\mathbf{0 , 5 2 )}$ com Desempenho Individual.

A primeira contribuição apresentada por esta pesquisa foi: A análise de elementos amplamente abordados no referencial teórico, num modelo que permite examinar o quanto cada um influencia o desempenho individual. Tal contribuição permitirá a evolução de análises, o aprofundamento nos elementos propostos e a ampliação do estudo para outros setores além da TI. A segunda principal contribuição foi: Os resultados empíricos de Desempenho Ativo dessa pesquisa confirmaram as pesquisas teóricas de (FOGAÇA et al., 2018; FRESE et al., 1994; FRESE et al., 2001; SONNENTAG, 1998).

Sob o ponto de vista gerencial, a principal contribuição deriva do modelo conceitual proposto, que pode colaborar para orientar a organização rumo a um melhor desempenho individual, isso considerando que a pesquisa evidencia elementos que estatisticamente foram aceitos como significativos em relação ao desempenho. Outra consideração a respeito do modelo é a força das relações encontradas entre Confiança na Organização $(\beta=0,57)$ e Identificação Organizacional, Identificação Organizacional $(\beta=0,47)$ e Motivação e Motivação $(\beta=0,52)$ e Desempenho Individual, demonstrando que investir em ações voltadas para o fortalecimento desses três construtos pode impactar positivamente o desempenho individual.

A pesquisa foi realizada em empresas do setor de TI (Tecnologia da Informação), maioria em Minas Gerais, por meio de uma amostra de natureza intencional. Apesar dos questionários serem respondidos, procurando abranger o maior número de respondentes, devido à natureza não probabilística da amostra, faz-se necessário esclarecer que ela não representa todas as empresas do setor de TI brasileiro e nem outros setores. A sugestão de futuras pesquisas para o avanço do conhecimento científico e prático são que pesquisas empíricas, no tema dessa pesquisa, sejam realizadas em outros setores, que não seja $\mathrm{TI}$, e com amostras maiores, usando o modelo teórico sugerido na figura 1 para validação do mesmo.

\section{REFERÊNCIAS}

ARAÚJO, P. M.; OLIVEIRA, Á. F.. Bem-Estar no Trabalho: impacto das percepções dos valores organizacionais e da confiança do empregado na organização. Programa Institucional de Apoio à Iniciação Científica, Uberlândia, v.1, n.1, 2008

BATISTA, R. L.; OLIVEIRA, Á. F.. Antecedentes da confiança do empregado na organização. Estudos de Psicologia, p.247254, 2012.

BEAL, D. J.; WEISS, H. M.; BARROS, E.; MACDERMID, S. M. An episodic process model of affective influences on performance. Journal of Applied Psychology, v.90, n.6, p.1054-1068, 2005.

BENDASSOLLI, P. F.. Desempenho no trabalho: Revisão da literatura. Revista Psicologia Argumento, Curitiba, v.30, n.68, p.171-184, 2012.

BERGAMO FILHO, C.. Ruptura no modelo tradicional das empresas. Rio de Janeiro: Brasport, 2019.

BORGES, L. O.; MOURÃO, L.. O trabalho e as organizações, atuações a partir da psicologia. Porto Alegre: SBPOT, 2013.
BORMAN, W. C.; MOTOWIDLO, S. J.. Expanding the criterion domain to include elements of contextual performance. In: SCHMITT, W.; BORMAN, W.. Personal selection in organizations. New York: Jossey-Bass, 1993. p.71-98.

BRITO, R. P.; OLIVEIRA, L. B.. A Relação entre Gestão de Recursos Humanos e Desempenho Organizacional. BBRBrazilian Business Review, Vitória, v.13, n.3, 2016.

CAMPBELL, J. P.. A theory of performance. In: SCHMITT, W. E.. Personnel selection in organizations. San Francisco: Jossey-Bass, 1993. p.35-70.

DINIZ, B. A.; MARCONATTO, D. A.. Confiança: um construto universal. In: Teoria das Organizações. 2010.

DIRKS, K. T.. Handbook of trust research. Northampton Edward Elgar, 2006.

DURSUN, E.. The relation between organizational trust, organizational support and organizational commitment. African Journal of Bussiness Management, v.9, n.4, p.134156, 2015. 
FOGAÇA, N.; REGO, M. C.; MELO, M. C.; ARMOND, L. P.; COELHO, F. A.. Job Performance Analysis: Scientific Studies in the Main Journals of Management and Psychology from 2006 to 2015. Performance Improvement Quarterly, v.30, p.231-247, 2018.

FRESE, M.; DIETER, Z.. Action as the core of work psychology: A German approach. In: TRIANDS, M. D. H. C. Handbook of Industrial and Organizational psychology. Palo Alto: Consulting Psychologists Press, 1994. p.271-340.

FRESE, M.; FAY, D.. Personal initiative (PI): An active performance concept for work in the 21st century. Research in Organizational Behavior, Amsterdam, v.23, n.2, p.133187, 2001. DOI: https://doi.org/10.1016/S01913085(01)23005-6

FRESE, M.; KRING, W.; SOOSE, A.; ZEMPEL, J.. Personal Initiative at Work: Differences between East and West Germany. The Academy of Management Journal, v.39, n.1, p.37-63, 1996.

LEE, K.. Ethical Leadership and Followers' taking charge: trust in, and identification with, leader as mediators. Social Behavior and Personality, p.1793-1802, 2016.

LEE, K. M.. Presence, Explicated. Communication Theory, V.14, n.1, p.27-50, 2004.

LUGOBONI, L. F.; ZITTEL, M. V.; LOPES, R. M.; CHIARETO, J.; CORREA, H. L.; LENNAN, M. L.. A influência da origem das empresas no gerenciamento e na avaliação de desempenho organizacional. Revista de Administração da UFSM, Santa Maria, v.7, n.4, p.662-677, 2014.

MATITZ, Q. R.; BULGACOV, S.. O Conceito Desempenho em Estudos Organizacionais e Estratégia: um Modelo de Análise Multidimensional. Rev. Adm. Contemporânea, Curitiba, v.15, n.4, 2011.

MOORI, R. G.; DOMENEK, A. C.. Análise exploratória da colaboração dos funcionários e do desempenho do planejamento colaborativo na Klabin S/A. RAM - Revista de Administração Mackenzie, v.8, n.2, p.11-37, 2007.

MURPHY, K.. Dimensions of job performance. In: DILLON, R.; PELLIGRINO, J.. Testing: Applied and theoretical perspectives. New York: Praeger, 1989. p.218-247.

NELSON, B.. 1501 Maneiras de premiar seus empregados. Rio de Janeiro: Sextante, 2014.

PERÉZ-RAMOS, J.. Motivação no trabalho: abordagens teóricas. Revista Psicologia USP, São Paulo, v.1, n.2, 1990.

SCHAUBROECK, J. M.; PENG, A. C.; HANNAH, S. T.. Developing Trust with peers and leaders: impacts on organizational identification and performance during entry. Academy of Management Journal, v.56, n.4, p.1148-1168, 2013.

SEARLE, R. H.. Handbook of Advance in trust research. Northampton: Edward Elgar, 2015.

SONNENTAG, S.. Expertise in professional software design. Journal of Applied Psycology, v.83, n.5, p.703-715, 1998.

SONNENTAG, S.; FREESE, M.. Performance concepts and performance theory. In: SONNENTAG, S.. Psychological Managment of Individual Performance. Baffins Lane: John Wiley \& Sons, Ltd., 2002. p.4-25.

ZAGENCZYK, T. J.; GIBNEY, R.; FEW, W. T.; SCOTT, K. L.. Psychological contracts and organizational identification: the mediating effect of perceived organizational support. Journal of Labor Research, v.32, n.3, p.254-281, 2011.

ZANINI, M. T.. Relações de confiança nas empresas da nova economia informacional: uma avaliação dos efeitos da incerteza sobre o comportamento organizacional. Cadernos EBAPE.BR, Rio de Janeiro, v.3, n.4, 2005.

ZANINI, M. T.; MIGUELLES, C. P.. O papel mediador entre confiança e desempenho organizacional. R. Adm., São Paulo, v.49, n.1, p.45-58, 2014

A CBPC - Companhia Brasileira de Produção Científica (CNPJ: 11.221.422/0001-03) detém os direitos materiais desta publicação. Os direitos referem-se à publicação do trabalho em qualquer parte do mundo, incluindo os direitos às renovaç̃oes, expansões e disseminações da contribuiç̃o, bem como outros direitos subsidiários. Todos os trabalhos publicados eletronicamente poderão posteriormente ser publicados em coletâneas impressas sob coordenação da Sustenere Publishing, da Companhia Brasileira de Produção Científica e seus parceiros autorizados. Os (as) autores (as) preservam os direitos autorais, mas não têm permissão para a publicação da contribuição em outro meio, impresso ou digital, em português ou em tradução. 